\title{
Growing Up in the 'Digital' Age: Chinese Traditional Culture Is Coming Back in Digital Era
}

\author{
Situ Xiaochun
}

\begin{abstract}
This work focuses on how going 'digital' had an impact on and still influences Chinese culture. After a period in which Chinese tradition and culture has been undermined, since the 1980s until now China has entered a phase of rapid economic development, but the development of culture and education has not always equally kept pace. Universal education is still a problem for China, and Chinese tradition risks becoming a 'relic'. Now, we want to rebuild our culture, get back our traditions. With digital technology, getting knowledge from our history becomes easier for everybody. It will let people understand tradition faster, and be educated faster. It will also let us protect our cultural heritage better. This chapter also investigates how Chinese artists work with the 'digital' and how Chinese people are experiencing the cultural changes of this digital era.
\end{abstract}

\section{$1 \quad$ Foreword}

I am a Chinese artist born during the Cultural Revolution (an isolated and chaotic period), grew up during the period of economic reforms (a period of cultural and conceptual subversion), matured in a period of information explosion (where the digital has had tremendous impact on society), and am now striving for a better life in the age of digital revolution (where digital technology is taking over the world). As someone living in the digital world, I have experienced many shifts in cultural values and social transformations. I hope I can use my experiences to provide an additional insight and understanding on how the 'digital' changed China, as well as its impact on cultural production in China.

\section{S. Xiaochun $(\square)$}

Situ Sculpture Art Studio, Beijing, China

e-mail: situxiaochun@gmail.com 


\section{The 1970s: "There Was Almost no Television, One's Family Was the Cultural Oasis"}

My childhood was simple and boring. Culturally speaking, China was enclosed and isolated at that time. Both my parents are artists, and their jobs were assigned by the state. They were always busy and had to travel for work, so I rarely saw them. At that time, what you ate, drank, learned, listened to, looked at, or even the person you would marry were planned. Money was useless, because the meat and the eggs you received per month were rationed; even if you had money, you would not be able to purchase anything. During that period, people did not have any way of getting entertainment, cultural activities or personal space, because almost all of your personal time was taken, and everything was planned. You were only allowed 1 day off per week, and you would be exhausted after taking care of your home. Visiting the Forbidden City with my parents was a rare treat; it is ironic that all the teachers, media and people said: "we have happy life" in that period, while I remained doubtful of 'this happy life'. In an era of material scarcity, one's spiritual life was not the concern for most people, where 'culture' seemed unreachable.

I lived with my grandparents. My grandfather was a historian, who liked to read late at night. He saw I was bored, he gave me Romance of the Three Kingdoms to read-a classical text portraying China in the 1800 . The characters written in this book were the traditional ones - those used in 200 A.D., a traditional way of writing developed from pictorial characters. From 1956, Mainland China adopted the simplified characters to replace the traditional. People of my age no longer had to study traditional characters in school. There was no punctuation in this book, which made reading quite tiresome, but soon, I got used to it.

It was only after I grew up that I realised that Chinese literature was developed from pictorial characters, and every character originates from a visual symbol. In other words, writing Chinese is like drawing an image. However, the simplified characters terminated the relationship between language and its visual form, as well as its connection with traditional culture.

Chinese calligraphy is a visual art based on the structure of the characters, using text to convey the content and meaning through self-expression. The critical essence of this artistic form is how the artist carries out the text in the content of his expression through the energy he exerts on the page. The simplified characters lack the structural and visual relationship in its writing, which is not apparent to the calligrapher. This is also the reason why calligraphers today are still writing in traditional characters, and their content is still primarily classical poetry. This is probably also due to the essential flaw of simplified characters being unsuitable to practicing calligraphy.

The simplified characters were invented for practical reasons and in fact they can save a lot of writing time. As people started to use simplified characters widely, their ways of thinking also began to change. More practical ways of painting were also developing - for example oil painting - and realistic forms began to replace abstract and symbolic concepts of Eastern painting, or ink painting that focuses on rendering the form. 
The initial goal of simplified characters was to get rid of excess strokes in a character, so as to improve writing efficiency. Today, with the emergence of computer and digital portals, people's necessity to write is reduced, and like the Chinese phrase says "always forget how to write some words when they take up the pen". Yet with the emergence of computers, pinyin input method initiated another revolution. Thus, I think this may be the time to reinstate the usage of traditional characters, because the complication of writing is no longer an issue.

Ultimately my childhood was uneventful, every day was the same, getting up, lining up, having my name called, being criticised, . . but everyone tells me that my childhood was happy, why did I never feel it was? What is culture? What is art? I had no idea. What are other people doing? What does elsewhere look like? Why are foreign countries mesmerizing? These are the questions I wondered at that time.

\section{The 1980s: “What Might Have Been Wrong May Be Right, We Seem to Look at New Things"}

With the opening of the economic reforms, myriads of new things rushed into the country. I thought music was supposed to be sweet, yet it sounded like mad people screaming and this was considered a famous tune. People began to make money. While in the past our teachers would tell us that being a materialist is bad, some people began to buy expensive clothes, and the teachers were still saying "It's not good to focus on vanity". Some people played guitar by the side of the street, and the teacher said they were products of capitalist class. I was a teenager, and began to think money was good, that it was nice to wear nice clothes, play guitar and dance disco, making me feeling free. So did I become bad? Life became more interesting, I wanted to listen and look at new things, I wanted freedom to express myself, so I decided to study art.

The economic reforms opened a window through which we could see the world, I remember that many people began to suspect that their life was not how it should be. People's desires became insatiable, the change made people look for a new life.

The telephone became popular, a household item in many families. Even though it was still an expensive item, its availability brought people closer. Television also became a necessity in every household, and many were colour televisions. The daily news after dinner was a way people learned about what was happening in the world. All these phenomena are attributed to the economic reforms, when it became possible to make money and to buy things as one wished.

I still rarely saw my father, because he had to travel abroad or out of town. My mother said he had to give lectures to government administrators on urban building and sculptures. It was a period when making urban building and city sculptures was booming.

Because of my father's love for music, he brought back a Sony Stereo system, which had a CD-player-still a rare device at that time! As the CD was recorded digitally, it had better sound effect than audio-cassette, so we could better enjoy the music we liked. In fact, I had not heard before any music I enjoyed. From then on, I 
discovered music such as Carmen and Swan Lake with my father. I did not like the sound of the violin, but I enjoyed listing at the clarinet, I was mesmerised by a concerto played with clarinet and cello.

After 1985, my father gave me two CDs that foreign friends of his had given to him; he thought they were good, but were not his style. One was by Madonna and the other by Michael Jackson. I must admit that I was shocked discovering that music can sound like that! I began to look for that kind of music, it was not easy, I re-taped from others, but what was available was rather limited.

At the end of the 1980s, I began to learn rock n' roll, but any material was difficult to find, and even teachers at the music conservatory were unfamiliar with that genre. Any foreign material on the subject was valuable, and it was copied until the text was illegible.

In 1988, I decided to study art. The decision was partially due to the new era, which opened up new ways of seeing myself and what I could do. The affiliated high school of the Central Academy of Fine Art taught classical art; it is still the best art school in the country, and also the most difficult to be enrolled at. It was one of the few high schools in the country that opened up its admission nation wide; it was a lot more competitive than other schools.

Chinese students are under greater pressure than most Western students. I had to get up at 7 in the morning to go to school, and came home at 5 in the evening. The first thing I had to do was to draw 30 sketches, and then quickly have dinner, then draw another $4 \mathrm{~h}$ of sketches, then quickly finish all my homework, sleep for $6 \mathrm{~h}$, then the day was completed. On the weekend, I had to paint a gouache. This kind of training went on for 3 months, repeatedly, over 90 days. Eventually, I was lucky to pass the exam. This was due to the right training methods: my father trained me in sketches-he is an acclaimed sculptor in China, who studied in the former SovietUnion-; and Mrs. Pang Tao, a master in colours in China, a friend of my parents, helped me with colours. They were all professors of the Central Academy of Fine Art.

For artists, catalogues are important, and luckily, I have been able to see many of them with my parents. However, for a regular Chinese family, at that time, the art catalogues were extremely rare, since $2-3$ months salary of both parents may only be sufficient to buy one art catalogue. In the present digital era, even though very expensive catalogues still exist, we can use our mobile phone to look at the best art works in the world. This was not possible at that time.

Compared with other countries, China was a country with limited pedagogical resources. Still now, there is a significant disparity between the city and the countryside. Going to school and finding a job in a city can change the fate of the entire family. Thus, from the 1980s, competition in pedagogical resources became fierce, and even mad. The digital era blurred the boundary of intellectual fields. In the past, it was difficult to gain knowledge about other fields than those you were involved into. Vice versa, now, all you have to do is to use a search engine on the Internet to find relevant materials, which you can make up to in a few minutes. 


\section{$4 \quad$ The 1990s: “Discovering a New World, Mad About 'Digital'"}

The Internet arrived. In the mid 1990s, the Internet came to China. It was in 1996 that people started to use the Internet for personal use, but it was only between 1998 and the 2000 that the Internet started to be widely used outside the work place. During the 1990s, computers had not yet entered into people's home, and only a small number of professionals were using them. Most of the servers were located outside of China, bandwidth was limited, and speed really low. Nevertheless, it was another portal to the world. We began to retrieve knowledge from the world freely, and to establish a dialogue with the rest of the world. If the 1980s economic reforms opened the door to a new economy, then the Internet in the 1990s opened the door to new information. The rapid rise of the Internet, and the birth of Chinese websites, created the conditions for every urban family to have a computer and a telephone dial-up. The explosion of the information era arrived: people started to use email to communicate, read news on webpages, chat on social network software, play Internet games, etc. In just a few years, the Internet changed the way of life, especially for the young generation, and our distance from the rest of the world became shorter.

At the beginning of the 1990s, I was enrolled at the Central Academy of Fine Art and began to study sculpture. At the time, the computer was a hot topic, and my curiosity propelled me to learn. In those years, the computer had not yet entered private homes; it was used only by professionals and technology experts. As a student of an art academy, it seemed unreachable for me. It was because my uncle was a computer engineer, that I had the opportunity to come in contact with computers, and learned how to use them-my family resources helped me again. A lot of my creative proposals were developed on the computer, taking 3-5 days to complete jobs that nowadays take only $3-5 \mathrm{~h}$.

Virtual and interactive technologies started to become popular, most typically, through computer games. Computer games were something that did not exist in my childhood, and it was only in the 1990s that I began to play games on the computer. The games provided a virtual environment, where I could do things beyond my actual real life, such as to pilot the airplane and learn, for example, how to use the gauges to take off and land, use weapons, radar, etc. At the same time, it was also a way to acquire knowledge on geography. After the year 2000, competitive games became more developed, requiring gamers to develop more accurate operational skills, perfect team collaboration, logical strategies. International competitions became widely popular, e.g. e-sport. I discovered that by playing a game that applies virtual and interactive characteristics of digital technology, one learns and nurtures various abilities through entertainment. The negative aspect was that many players became addicted and took refuge in their 'virtual lives', missing out on having a role in their real lives. For instance, they felt that by such gaming they could have a sense of achievement, have power, have relationships, say whatever they wanted. In the end, these people drifted farther and farther away from reality. 
From the late 1980s, I spent a lot of time learning music and playing guitar, and organised many bands in high school and university, but I finally stopped in 1994. The 1990s was a nervous and restless era, everyone was busy making money, looking for a way out to change their lives. It was an era of opportunities, and it was difficult to find people with the same desire in creating music I was interested in. While computers can make digital recordings, and it is possible to edit the piece through various software, it was very difficult to organise live performances. But, at least, thanks to the digital, I was able to make music, and the work that had to be done previously with a team, was now possible to be completed autonomously. However, where musical composition becomes more personal, the work becomes quite lonely. What could have been created, previously, through spontaneity and interaction, with the digital it changed, and the creative input of the team was lost. Under the commercial drive, many successful bands signed up with music production companies. Many of those were individual contracts where the members of the band could be replaced at any time, and the instrument players were, in the better circumstances, only workers doing their jobs, with a lack of creativity. In this case, musicians had their survival conditions worsened; they were only called on to work for recording and performances, but were not involved in the creative processes. In the fast food style cultural era, with the help of digital technology, the making of pop music became especially easy. I have a friend who was a composer of pop music; now he often works with software to compose at home, moving back and forth a few parts enabling him to rapidly finish a few songs. This is commercial output, and there are countless customers in China, so products like this still have an enormous market.

In the summer of 1997, a British art school came to give lectures in China. Many lectures were on multi-media art. They introduced artworks completed on the computer by using digital technology. There was one work where the viewer could click on the various rooms in student dorms or offices with a mouse to see what is taking place in these spaces. With interactivity, the viewer may enter the art work through his/her own understanding and viewing habits. Various ways of viewing give different outcomes, digital technology is providing new methods for artistic expression.

Based on the interactive element, the digitally rendered work of art has also broken down our linear way of understanding time, as well as the elements of the 2D painting and space. It provides more creative possibilities so that the virtual space expands our space for thinking how sound, light, and electricity may be integrated into one. It was then that I was deeply mesmerised.

My focus at the University was on sculpture, while I also studied digital imaging and 3D. In fact, personal computing did not yet have the cutting edge technology in multi-media. In the 1990s most people were dilettante and were just beginning to learn about graphic design, advertisement, animation and, later on, attempts in making digital music. 


\section{The 2000s: “The Self Has Been Changed by the Digital, One Cannot Live Without Electricity"}

The real digital era is imminent. As the new century dawned, I realised could no longer live without a computer. I could no longer write with a pen and paper, my drawings are done on the computer, and the materials for ideas are 'digital', which included videos, soundtracks, interaction, uploading, spreadsheets, programs, and annotations.

The way I thought was different from that of the people around me-often I wish I could just press CTRL $+Z$ key. My curiosity towards the outside world became less, even new digital methods and novelties were not as appealing as they had been, and the necessity to reflect became more urgent.

Around the year 2000, digital technology rushed into traditional media, such as photography. Once expensive products, photographs became digital files. One day I suddenly realised I no longer cared about my photo album, and it was left in the corner to gather dust. Everything could be seen on the screen, and I bade farewell to my regular photo processing shop, replaced now by digital printing. Photography habits also changed from the analogue era: previously it was necessary to set the camera up to perfection and find a sufficiently perfect moment to press on the shutter, and almost every composition was excellent. In the digital era, with zero cost for post-production, I became almost careless about composition, because images can be edited after they are taken. Neither do I care too much about how to set up the image properly, I could take a shot with every shutter speed and focal length, thinking that I can look at them afterwards. The 'digital' made my photography habit rusty. At the same time, in the past there were only a few people who had cameras because they really loved photography; now, everyone has a digital camera, can take photographs, and use various fool-proof software for post touch up. What was highly technical, became common usage, the era of 'everyone is a photographer' is here.

Free access and information sharing are the basic concepts of the Internet. With the Internet, I rarely go to the bookstore anymore, because the amount of information available online allows me to learn whatever I want.

The Internet changed not only the path by which we acquire knowledge; the impact of the Internet on artistic consumption is also revolutionary. This is the case for music, for example. We can listen to music for free, and a very vast amount of information is accessible without borders. Popularisation of music is also a benefit brought forth by the digital age. Availability of rich and free resources allows more people, including the impoverished ones, to enjoy musical culture. What is surely worth celebrating is that music from all corners of the world is brought to our finger tips. Many Chinese of my generation were not be able to enjoy a live concert, nor did they had the financial means to learn music or buy CDs. With the beginning of the digital era, these people may buy an inexpensive computer, enjoy music from around the world, and use the computer and the Internet to learn music. All this was 
unimaginable before. At the same time a more negative aspect is that many musical companies have been forced to transform because musicians could no longer make money through launching records, they had to do tours to support their livelihood. The low entrance standard broadened the scale of popular music, but also altered its value due to the demand for entertainment that imposed the fast-food model of popular music. In this vicious cycle, music became cheaper and cheaper and lower in quality.

\section{The 2010s: "Realizing I am a Member of the World"}

In recent years, with the popularisation of smart phones and the infrastructure of wifi, 'digital' living began to affect all aspects of our lives. Most Chinese own one or many digital portals, and China has formally entered the digital era, and the 'digital' is making drastic changes to society.

I live in Beijing, a densely populated city where it can be quite suffocating. Shopping at the supermarket is an unavoidable chore, although with the boom in Internet shopping in recent years, I almost do not have to go to the shops anymore. All daily necessities can be purchased online. I no longer need to be worry about pricing, because it is easy to compare prices around the world. Neither do I have to worry about traffic and expensive parking fees because I can plan my movements earlier online. And since e-vendors have lower costs for their physical premises, their prices are often cheaper than the shops. The low labour cost allowed logistics to develop, which also promised the development of e-business.

I often speak to many Chinese artists about the ideal of digital art. Most people think digital equipment is convenient; it offers the possibility to explore new forms of expression; and it serves the curiosity of getting out of technological blindspots. In my view, these are not forms of digital art. As one poet friend of mine says, "The one who is poetic at heart is a true poet." Similarly, I think an artist should first be artistic "at heart"; then, when he/she thinks digitally, and uses a digital language, they can be a true digital artist. If you use a digital camera to imitate the effect of a film, I do not consider this digital art, because it does not consist of elements of digital language. Similarly, playing rock n' roll with 'overdrive' timbre is the proper language of the electric guitar.

The language of digital art is what I am interested in. In order to apply this new artistic language, it is necessary to adopt a digital way of thinking, and I believe that, in this way, many artists like myself are exploring digital art.

\section{Contribution to Traditional Art in the Digital Era}

What Chinese culture refer to as 'culture' is not necessarily the concept we translate from the West, but includes 'language and education'. For this reason, we appreciate digital technology and the resources made available on the Internet, because they provide an opportunity for many persons to learn about cultural heritage. 
Moreover, it is the explosion of information through digital means that has allowed many people to have 'crash courses' in a short period of time and to quickly retrieve information on the traditional Chinese civilisation that has previously been overlooked.

For example, in August 2013, a netizen recorded the collapse of Longtian Temple at Xilianghe village in Shaanxi Province, and uploaded it on Weibo. In June 2014, the official Weibo account of China Daily reposted this video calling for a social response. Subsequently, the China Daily newspaper featured a special report calling on the protection of cultural heritage. In January 2015, the formal restoration project was launched, and by the end of the year, the project is planned to be completed.

There is much cultural heritage that is unknown to the public, like the Longtian Temple, housing valuable ancient murals, architecture and sculptures. In past years, these historical relics were not protected or studied. Digital technologies have provided convenient and multi-media platforms of communication that call the attention of the society and the government to protecting cultural heritage. Also, digital technologies can be used to supervise the progress of restoration of cultural heritage, so that valuable cultural relics may be better protected and the general population may gain knowledge of these art works.

In China, with the prosperity associated with its economic development, culture is gradually receiving more attention and more resources are allocated to cultural programmes. The 2014 governmental budget increased spending on supporting the protection of cultural relics in order to propagate the legacy of Chinese culture and tradition. According to data published in the newspapers, the central administration has allotted 88.43 billion RMB in 2014 , which was 11.1 billion RMB more than 2013 - a $14.35 \%$ increase. The fund for cultural relics protection is primarily used for important national heritage, national immaterial cultural heritage, and the projection plan for national antique books and associated archival projects.

\section{Conclusion}

Looking at the other chapters of this book, it becomes evident that Europe is deeply interested in researching the relationship between digital technology and cultural heritage over a longer time frame, while China has just begun. Museums and libraries are still working on building basic database structures and have started recently to develop a digital diffusion of culture. There is a gap between Europe and China, but in more recent years, the Chinese government is investing more and more in this area, and Chinese cultural and academic institutions are very active in the sector.

From the 1990s, China's digital and communication technologies developed very fast, and they are now almost synchronised with the rest of the world. Network 
and virtual technologies influenced China as they did the rest of the world, and since the start of the twenty-first century, China has entered the process of globalisation, and this applies also to digital technologies.

Further, digital technologies have allowed a stronger impact and fusion with foreign cultures, letting multicultural experiences develop again in China. It has led to a profound impact on the society and on individual people's values, lifestyles, and social structure - everything is changing. I quite agree with many experts, who argue that building a global unified Internet management and specification is becoming a priority, not only for the sciences but for the arts too.

Digital technology has brought the development of the concept of 'multiculture', and as a Chinese artist, I have an open mind, different perspectives from before and the possibility to communicate with the world. Heteromorphic Space series (Figs. 1,2,3) is my recent work. I developed this idea by applying the language of digital 3D technology. I used virtual material as an artistic material. I researched it and then moulded in the virtual and then created it in the physical. Comparing the virtual material with the real, I developed a different understanding of shapes, and found a new artistic language. This series of works fully reflects the fact that the digital technology influences thinking and perception. I used the concept of digital elements, such as average, quantification, virtual realism, the dynamic, visual rationalisation, and symbolism. Finally, in these works, I expound and discuss the differences between human subjective thinking and the objective world that occurs with digital elements. Heteromorphic Space is a testimony of the new possibilities opened by the digital to artistic research.

What has the 'digital' contributed to China? In addition to opening new perspectives to digital art, I think that the most important impact of the digital on the society derives from its openness and its way of disseminating education among the public. Knowledge became accessible more quickly and easily to everybody, and this satisfied most people's desire for culture, improving the level of education. Opening up people's ways of thinking challenged the status quo and resulted in positive side effects in the whole society. This includes: how the protection and preservation of heritage through digital means increased the public's interest in traditional culture; how maximisation and explosion of information decreased people's more simplistic curiosity, giving space to enter into a phase of reflection, and a return to Eastern way of thinking. Live interaction and virtual communication has broken down the spatial distance and the confines of class, even generating influence on the political realm; globalisation of culture, and a return of selfconsciousness, moving from obtuse points of view to reflection. It has progressed our thinking. We are living in an era where Eastern culture cannot be any more marginalised, and the 'digital' allows Chinese culture to have a new role in our life, in China and abroad. 


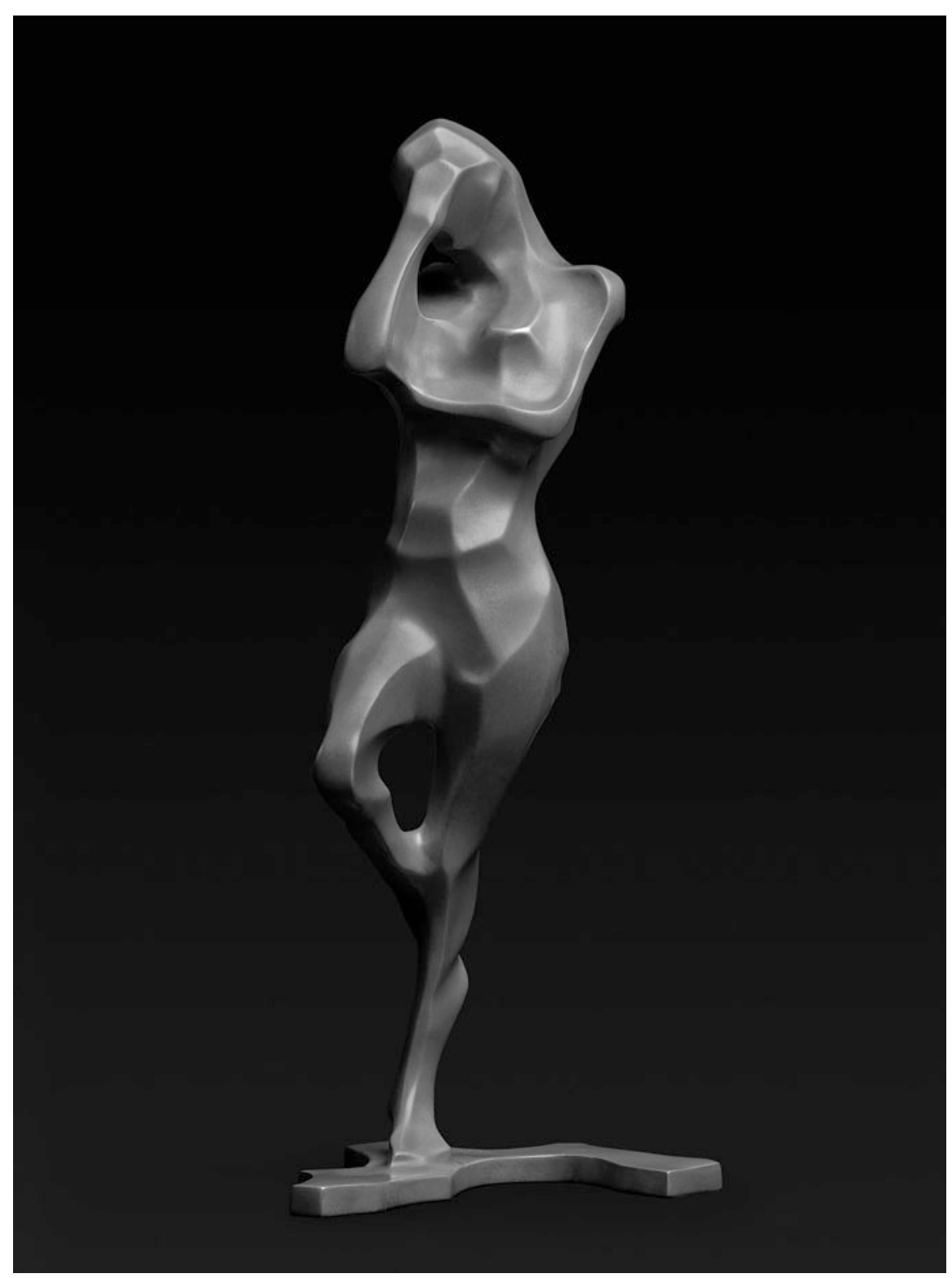

Fig. 1 Standing, 2014, $40 \mathrm{~cm}$, cupronickel, (Photo: Yang Chao) 


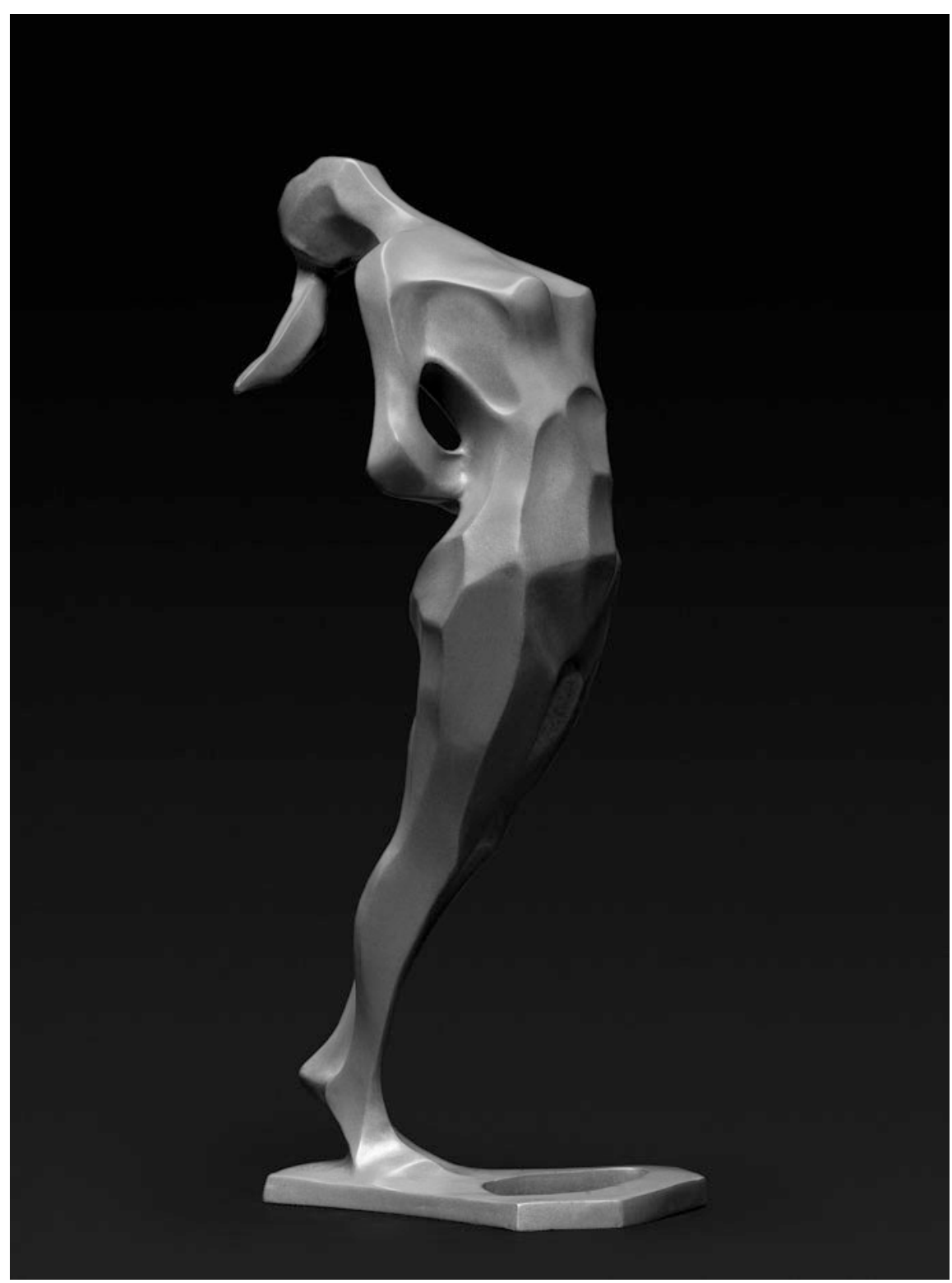

Fig. 2 Opening, 2014, $40 \mathrm{~cm}$, cupronickel, (Photo: Yang Chao) 


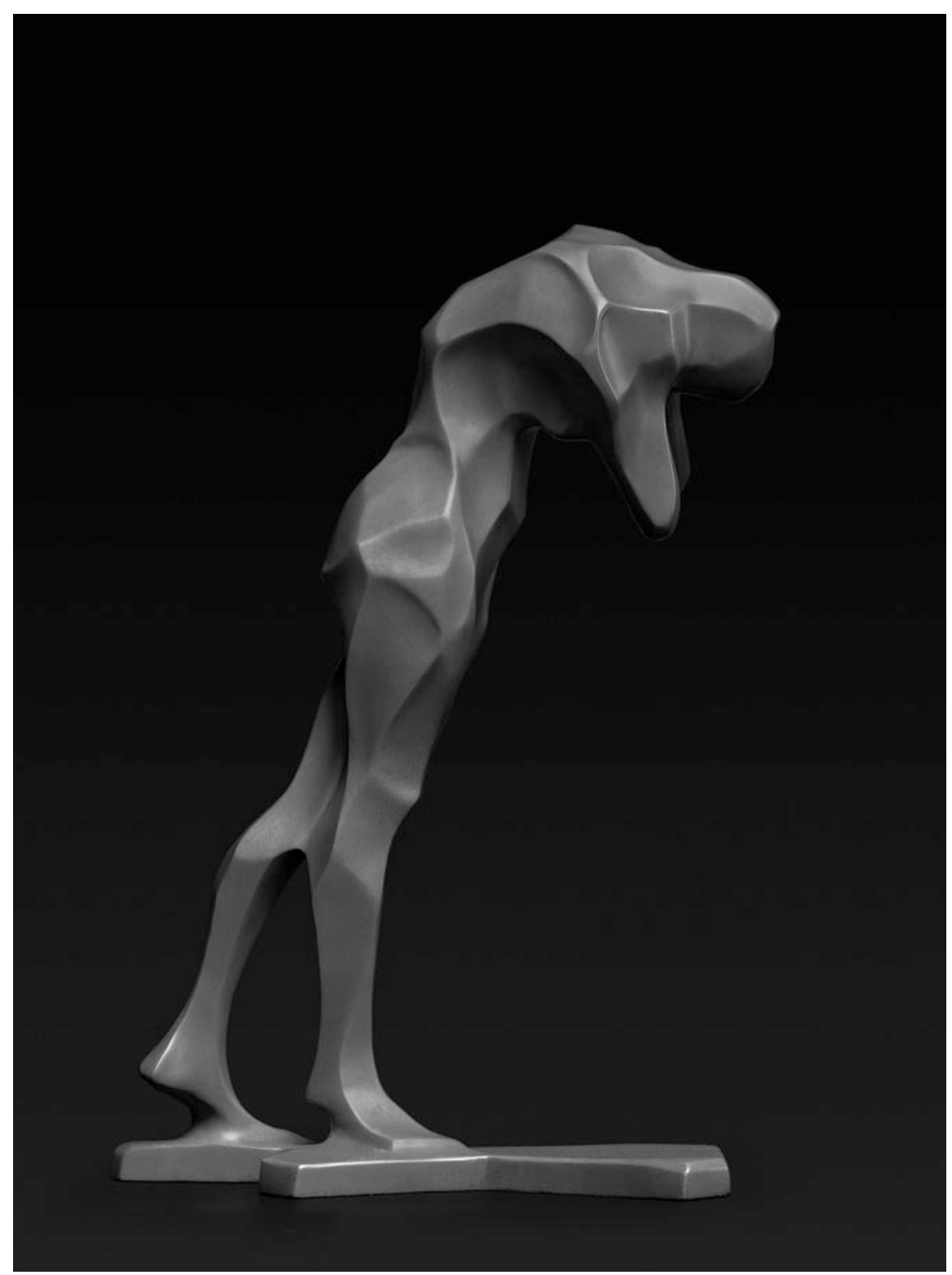

Fig. 3 Walking, 2014, $40 \mathrm{~cm}$, cupronickel, (Photo: Yang Chao) 
Acknowledgment The author gratefully acknowledges comments made by Elisa Debernardi and May Pettigrew on a draft of this chapter.

Open Access This chapter is distributed under the terms of the Creative Commons AttributionNoncommercial 2.5 License (http://creativecommons.org/licenses/by-nc/2.5/) which permits any noncommercial use, distribution, and reproduction in any medium, provided the original author(s) and source are credited.

The images or other third party material in this chapter are included in the work's Creative Commons license, unless indicated otherwise in the credit line; if such material is not included in the work's Creative Commons license and the respective action is not permitted by statutory regulation, users will need to obtain permission from the license holder to duplicate, adapt or reproduce the material. 